\section{Intralobar pulmonary sequestration treated with video-assisted thoracoscopic lobectomy}

\author{
Taeyun Kim, ${ }^{1}$ Hyunji Choi, ${ }^{2}$ \\ Jehun Kim ${ }^{1}$ \\ ${ }^{1}$ Department of Pulmonology, Kosin \\ University Gospel Hospital; \\ ${ }^{2}$ Department of Laboratory Medicine, \\ Kosin University Gospel Hospital, \\ Busan, South Korea
}

\begin{abstract}
Bronchopulmonary sequestration (BPS) is a rare congenital anomaly of airway in which a portion of the lung receives blood supply from an abnormal systemic artery. A 72-year-old woman had been suffering from recurrent left lower back pain and pneumonia for more than 10 years. She was diagnosed with intralobar type of BPS by computed-tomography angiogram and underwent video-assisted thoracoscopic lobectomy. BPS is a rare congenital abnormality that can accompany repeated pulmonary infection. Although asymptomatic patients may consider lifelong observation, surgical treatment of patients with symptoms is a curative option with minimal morbidity. To improve quality of the life for patients, active surgical treatment should be considered.
\end{abstract}

\section{Introduction}

Congenital malformations that can occur in the lung include congenital lobar over-inflation, cystic adenomatoid malformation, bronchogenic cyst, pulmonary sequestration, bronchial atresia, and foregut anomaly. Corbett et al. reported 283 cases of malformation of the lung, and pulmonary sequestration was the most common anomaly with 76 cases $(26.9 \%) .{ }^{1}$ Bronchopulmonary sequestration (BPS) is a rare congenital anomaly. BPS receives its blood supply from an abnormally originating systemic artery. BPS occurs at a probability of 1 in 10,000 to 35,000 of a newborn child. ${ }^{2}$ BPS is anatomically divided into intralobar (IL) type and extralobar (EL) type. IL type is more common than EL type and accounts for $75-85 \%$ of the total sequestration. ${ }^{3} \mathrm{We}$ herein report a rare case of IL type BPS successfully treated with video-assisted thoracoscopic surgery (VATS) lobectomy.

\section{Case Report}

A 72-year-old Asian female complained of left lower back pain for more than 10 years. The patient was diagnosed with pulmonary sequestration through computed tomography (CT) angiogram in 2008, but did not receive operative management. Previous histories of hypertension, diabetes mellitus, tuberculosis, or other diseases were denied by patient. She also denied smoking and alcohol drinking. On physical examination, normal breath sound was auscultated and no abnormal features were detected on inspection. Her vital signs were within normal limits. Laboratory results including complete blood count, C-reactive protein, and hepatic and renal function tests were unremarkable. In a CT angiogram performed in 2008, a low density mass like lesion of approximately $14.0 \times 11.4 \mathrm{~mm}$ size which is supplied by the artery originating from the thoracic aorta was observed in the left lower lobe (Figure 1). Follow-up CT scan in February 2019 showed increased low density lesion adjacent to the supplying artery (Figure 2). Because the size of the lesion was difficult for wedge resection and possibility of dissecting pulmonary vein, the patient eventually received a left-lower lobectomy with a VATS. After surgery, the patient was stabilized and discharged from chest-surgery department without any complications. Two months after discharge chest X-ray was taken (Figure 3), and the patient regularly visits our clinic with no complaints.

On pathologic examination, systemic feeding artery was found (Figure 4A). Inside the cystic cavity, the lining was unclear and filled with macrophages (Figure 4B).

\section{Discussion}

The pulmonary accessory lobe receiving aberrant blood supply was first reported by Huber in 1777 . Pryce used the term sequestration in 1964 for the first time in the pulmonary accessory lobe. ${ }^{4}$ Sade summarized the spectrum of BPS in 1974 and described sequestration as a defect of morphogenesis in embryonic thorax. ${ }^{5}$

BPS is divided into IL type and EL type depending on whether it has pleural covering. IL type BPS has continuous parenchyma with normal lung tissue, but EL type BPS has separated parenchyma with its own pleural covering. ${ }^{6}$ IL type accounts for $6.4 \%$ of total congenital lung abnormalities. The most common site is posterior basal segment. It is known that there are no gender
Correspondence: Jehun Kim, Department of Pulmonology, Kosin University Gospel Hospital, 262 Gamcheon-ro, Seo-gu, Busan, 49267 South Korea.

Tel.: +82.51 .990 .5820 - Fax: +82.51 .990 .5820 .

E-mail: libertier@gmail.com

Key words: Pulmonary sequestration; VATS; Congenital anomaly.

Contributions: all of the authors interpreted the patient's data and were responsible for the diagnostic assessment. TK was a major contributor in writing the manuscript. All of the authors read and approved the final manuscript.

Conflict of interest: the authors declare no potential conflict of interest.

Ethical statement: the patient provided written informed consent for the information and images to be published.

Received for publication: 3 July 2019

Revision received: 12 August 2019.

Accepted for publication: 29 August 2019.

This work is licensed under a Creative Commons Attribution NonCommercial 4.0 License (CC BY-NC 4.0).

(Copyright: the Author(s), 2019

Licensee PAGEPress, Italy

Chest Disease Reports 2019; 7:8374

doi:10.4081/cdr.2019.8374

differences in occurrence and location. ${ }^{7}$ About $73 \%$ of the total sequestrations are supplied from the thoracic aorta and 20\% from the abdominal aorta. About $5 \%$ of the cases are drained by systemic circulation and about $95 \%$ by pulmonary vein. ${ }^{1}$ Gross pathological findings include lack of anthracotic pigmentation or no bronchial communication. Whereas most EL type BPS occurs between the lower lobe and the diaphragm. ${ }^{7}$ About $80 \%$ of patients receive an arterial supply from the thoracic or abdominal aorta. Approximately $80 \%$ of EL type BPS are drained by azygos, hemiazygos, or inferior vena cava, and about $25 \%$ drainage by pulmonary vein. Gross pathological findings include unaerated or small pulmonary tissue with its own pleural investment. ${ }^{1}$ Recently, the venous drainage of BPS have been described as a possible source of infection in the presence of infected sequestrum and endocarditis in abnormal valve anatomy. ${ }^{8}$

The reason why BPS occurs is unclear. ${ }^{7,9}$ However, the mechanism by which IL type and EL type occurs is considered to be different. The EL type is thought to occur because the systemic artery pulls 


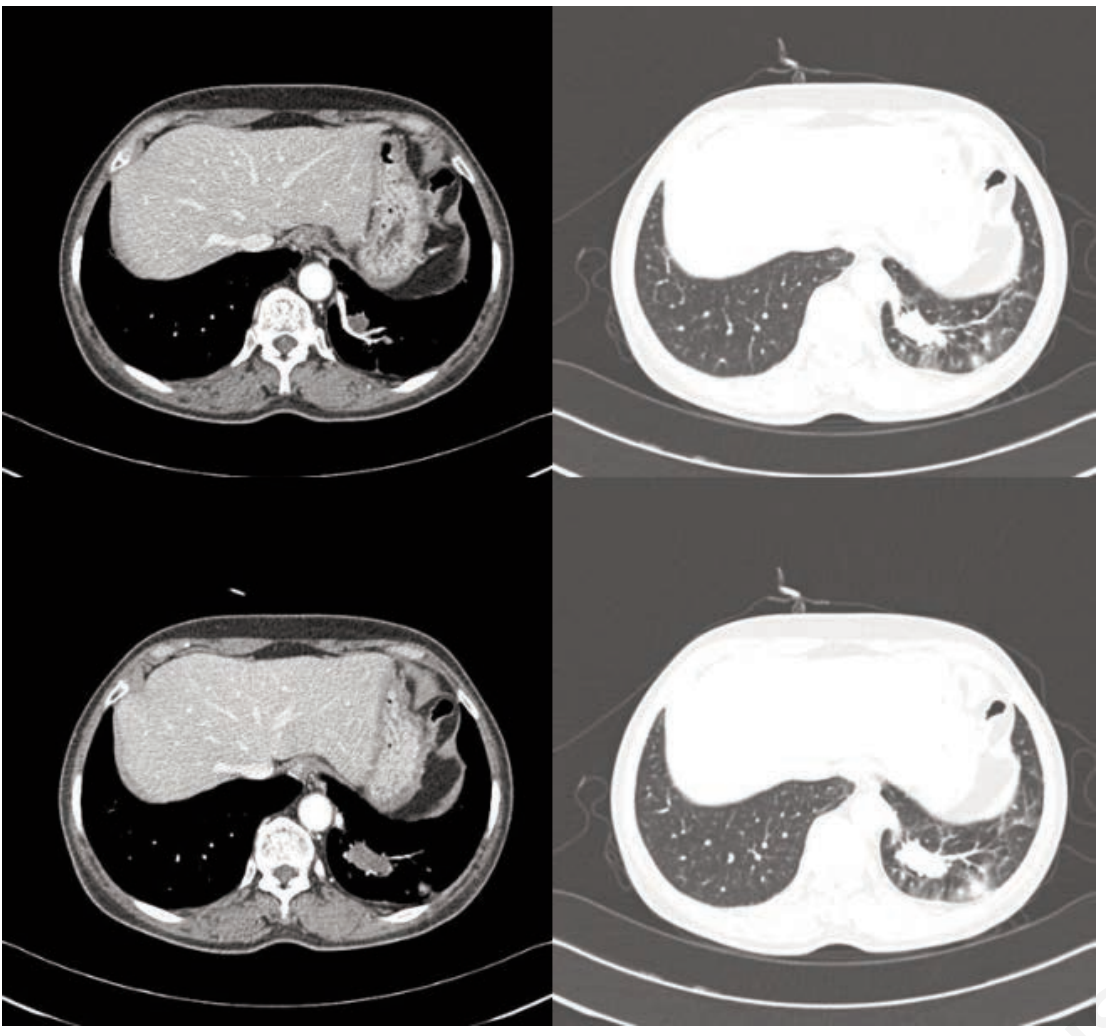

Figure 1. About $14.0 \times 11.4 \mathrm{~mm}$ sized low density mass like lesion in the left lower lobe which is supplied by the artery originating from the thoracic artery is observed in CT scan taken in 2008.

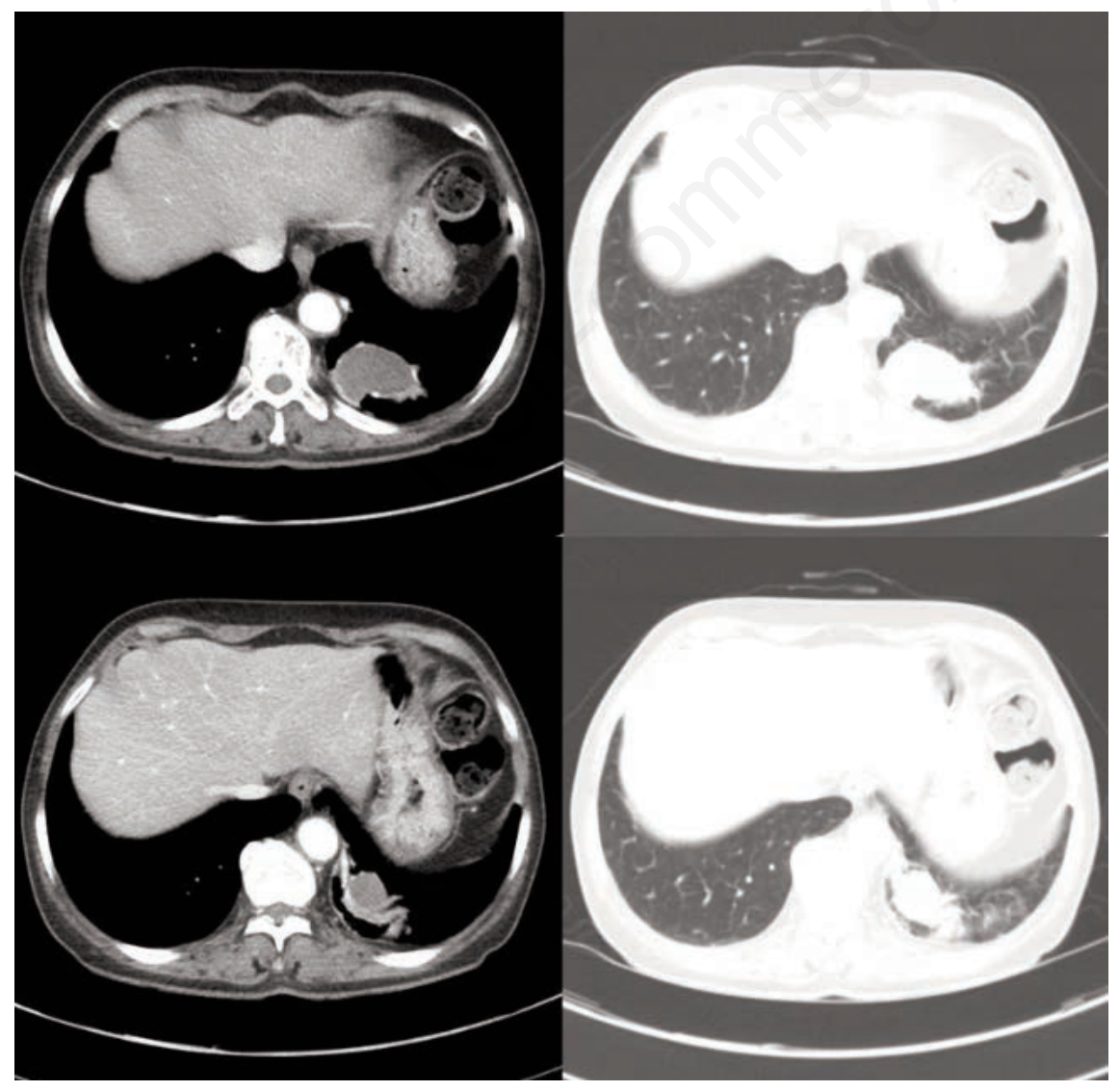

Figure 2. Follow-up CT scan taken in February 2019 shows increased low density lesion. the lung and separates it from the main lung mass. On the other hand, IL type is considered to be a result of development of the systemic artery as a result of pulmonary infection. ${ }^{10}$ There was also a report that genetically, homeobox gone Hoxb-5 would contribute to the outbreak. ${ }^{9}$

EL type of BPS is often asymptomatic and sometimes incidental when it is young. IL type of BPS is mostly found in adults with infection. ${ }^{1}$ CT angiography demonstrates the anatomy of lung parenchyma and BPS. ${ }^{11} \mathrm{CT}$ angiography may be the best

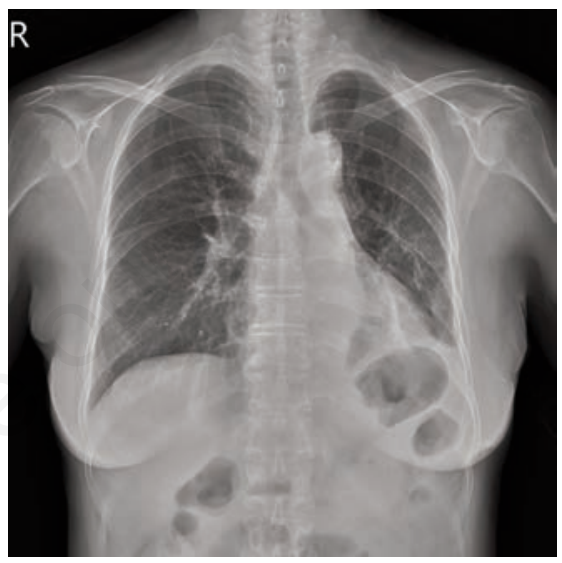

Figure 3. Follow-up chest X-ray image taken 2 months after operation.
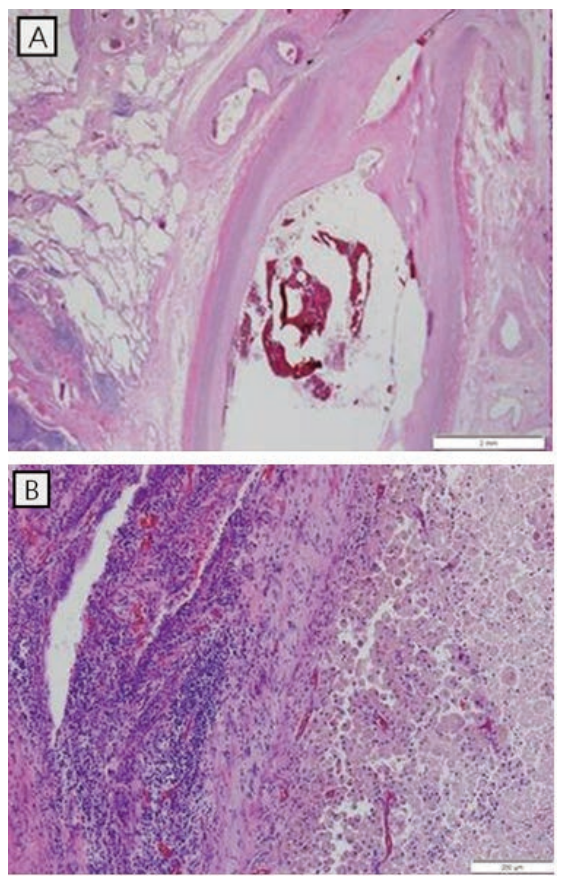

Figure 4. A) Feeding artery with thickened wall containing elastin and smooth muscles is observed (H\&E stain, $\times 200)$. B) Cystic cavity filled with macrophages on the right side is observed (H\&E stain, $\times 100)$. 
diagnostic procedure because it provides better visualization of blood vessels and venous drainage as well as anatomical structures. ${ }^{12}$ BPS is more than pneumonia. ${ }^{13}$ Surgical treatment for patients without symptoms is controversial. However, patients who have symptoms with repeated infections should undergo surgical excision. $^{14}$

\section{Conclusions}

Diagnostic technology has improved and BPS has become more easily diagnosed. BPS is a rare congenital abnormality that can cause repeated pulmonary infections. Although asymptomatic patients may consider lifelong observation, surgical treatment is a curative option with minimal morbidity. To improve quality of the life for patients, active surgical treatment should be considered.

\section{References}

1. Corbett HJ, Humphrey GM. Pulmonary sequestration. Paediatr Respir Rev 2004;5:59-68.
2. Durell J, Thakkar H, Gould S, et al. Pathology of asymptomatic, prenatally diagnosed cystic lung malformations. J Pediatr Surg 2016;51:231-5.

3. Tokel Kra, Boyvat F, Varan Bl. Coil embolization of pulmonary sequestration in two infants: a safe alternative to surgery. Am J Roentgenol 2000;175: 993-5.

4. Peyce D. Lower accessory pulmonary artery with intralobar sequestration of lung: a report of seven cases. J Pathol Bacteriol 1946;58:457-67.

5. Sade RM, Clouse M, Ellis Jr FH. The spectrum of pulmonary sequestration. Ann Thorac Surg 1974;18:644-58.

6. Van Raemdonck D, De Boeck K, Devlieger H, et al. Pulmonary sequestration: a comparison between pediatric and adult patients. Eur J Cardio-Thorac Surg 2001;19:388-95.

7. Savic B, Birtel F, Tholen W, et al. Lung sequestration: report of seven cases and review of 540 published cases. Thorax 1979;34:96-101.

8. Hui DS, Shavelle DM, Starnes VA, McFadden PM. Concurrent aortic valvular disease and pulmonary sequestration: clinical implications. Texas
Heart Inst J 2014;41:649-52.

9. Lin C-H, Chuang C-Y, Hsia J-Y, et al. Pulmonary sequestration - differences in diagnosis and treatment in a single institution. J Chin Med Assoc 2013;76:385-9.

10. Coutinho DJ, Dias MC, Oliveira MJ, et al. Bronchopulmonary sequestration presenting as a spontaneous pneumothorax. Respir Care 2015;60:e59-61.

11. Ko S-F, Ng S-H, Lee T-Y, et al. Noninvasive imaging of bronchopulmonary sequestration. Am J Roentgenol 2000;175:1005-12.

12. Kang M, Khandelwal N, Ojili V, et al. Multidetector CT angiography in pulmonary sequestration. J Comput Assist Tomogr 2006;30:926-32.

13. Borrelli EP. Maybe it is more than pneumonia: case report of an intralobar sequestration in a 20-year-old male. Respir Case Rep 2017;6:96-8.

14. Haller Jr JA, Golladay E, Pickard LR, et al. Surgical management of lung bud anomalies: lobar emphysema, bronchogenic cyst, cystic adenomatoid malformation, and intralobar pulmonary sequestration. Ann Thorac Surg 1979;28:33-43. 